\title{
The Correlation of Chloride Diffusion Coefficient and Concrete Maturity Value and Its Application in Hong Kong-Zhuhai-Macao Bridge Engineering
}

\author{
P. P. Li, S. N. Wang, and J. B. Xiong \\ CCCC Fourth Harbor Engineering Institute Co., Ltd. \\ R. Chai and Y. Yan \\ The Hong Kong-Zhuhai-Macao Bridge Authority
}

\begin{abstract}
The correlation of chloride diffusion coefficient and concrete maturity value within 56 days of curing was investigated by the chemically combined water content method, rapid chloride migration (RCM) test, and concrete maturity test. The experimental results showed that chloride diffusion coefficient of concretes decreased not only with increasing curing ages but also with increasing curing temperature, which can promote the hydration degree of cementitous materials. There is a significant correlation between the chloride diffusion coefficient of indoor cured specimens and the concrete maturity value when expressed as a power function $\left(R_{2}=0.976\right)$. In addition, the calculated values of concrete maturity for outdoor specimens, obtained using the power function, agree well with the measured values. As a result, the measured concrete maturity values can be used to predict the chloride diffusion coefficient of concrete. And then in this project, when the immersed tube tunnels were placed in seawater, the recommended value and the control values of concrete maturity were 21,064 and $13,926^{\circ} \mathrm{C} \mathrm{h}^{-1}$, respectively. Furthermore, the ages of the tunnels placed in seawater can be appropriately adjusted by calculation when considering the external curing temperature and heat of hydration of cementitous materials.
\end{abstract}

\section{INTRODUCTION}

Corrosion of steel bar induced by penetration of chloride in concrete cover is a frequent cause of degradation of reinforced concrete structures exposed to marine environment; thus, increasing the chloride threshold value and decreasing the chloride diffusion coefficient are the two important issues to improve the durability of concrete structures (Leng, 2000; Thomas, 2004; Wang, 2002). In high performance concrete construction of marine engineering, the resistance of concrete cover to chloride penetration must meet the design requirements; otherwise, it is difficult to meet the durability of design life. The resistance of concrete was not only related to the W/C ratio and the material composition but also associated with the curing temperature and the curing age ( $\mathrm{Li}, 2011)$.

In the 1950s, British scholar Saul put forward the concept of concrete maturity, which is shown in Equation (1). The initial strength of concrete can be calculated by a maturity-intensity curve, which is widely applied in guiding construction of concrete works (Wang, 2010), but the study of correlation between maturity and resistance to chloride permeability of concrete is rarely reported.

$$
M(t)=\int_{0}^{t}\left(\theta(t)-\theta_{0}\right) \mathrm{d} t
$$

As for some special concrete structures the durability of concrete cannot be assessed by coring method, this article studies the relationship between the maturity of short-age concrete and concrete chloride diffusion coefficient first, and then, using the correlation results, determines the reasonable ages to contact seawater for immersed tube tunnel. The results were expected to be used as a guide for the design and construction of structures to extend service life.

\section{METHODS}

\subsection{Raw materials}

The cementitious materials consist of Graded 42.5R Portland Cement supplied by Huaruan Cement in Guangdong Province, Graded fly ash with the density of $2230 \mathrm{~kg} / \mathrm{m}^{3}$ supplied by Jianbi Power Plant, and ground blast furnace slag with the density of $2930 \mathrm{~kg} / \mathrm{m}^{3}$ supplied by Shaoguan Iron\&Steel Plant. Washed river sand of fineness modulus 2.9 with the apparent density of $2650 \mathrm{~kg} / \mathrm{m}^{3}$ and the maximum size of the coarse aggregate $20 \mathrm{~mm}$ with the apparent density of $2690 \mathrm{~kg} / \mathrm{m}^{3}$ were used. High Range Polycarboxylate Water Reducer super plasticizer called PCA-I, supplied by Jiangsu Bote Material Technology Co. Ltd., was incorporated. 


\subsection{Experimental methods}

$X$ ray diffraction was performed with a $D / m a x A$ system supplied by Rigaku Corporation. The chloride diffusion coefficient of concretes is carried out according to the NT BUILD 492 (chloride migration coefficient from non-steady-state migration experiments). The IntelliRock maturity test apparatus invented by the United States Nomadics structure laboratory was used to measure the maturity directly, with the test ages of $3,7,14,21,28$, and 56 days. The hydration degree of cementitious materials can be characterized by using the determination methods of hydration water of slurry and selective dissolution (Shi, 2002; Zhang, 2006).

\subsection{Specimen preparation}

The concrete mix proportion is listed in Table 1. The cubic and cylindrical concrete specimens were removed from the molds after casting for 1 day. Then the specimens were placed in a concrete curing room and outdoors, respectively. Construction in different seasons may affect the anti-chloride-permeability performances of the immersed tube concrete. Therefore, in this part, the tests are conducted in two periods: summer (1st test) and winter (2nd test). There are some differences in outdoor temperature in the two test periods. The average outdoor temperature of the first test was about 25 and $18^{\circ} \mathrm{C}$ of the second.

Table 1. Mix proportion of immersed tube used high performance concrete $\left(\mathrm{kg} / \mathrm{m}^{3}\right)$.

\begin{tabular}{ccccccc}
\hline Cement & Slag & Fly ash & Sand & Gravel & Water & Sp \\
\hline 189 & 126 & 105 & 775 & 1047 & 147 & 5.04 \\
\hline
\end{tabular}

\section{RESULTS AND DISCUSSION}

\subsection{Concrete chloride diffusion coefficient under standard curing condition}

The influence of curing ages on chloride diffusion coefficient of concrete under standard curing condition is given in Figure 1.

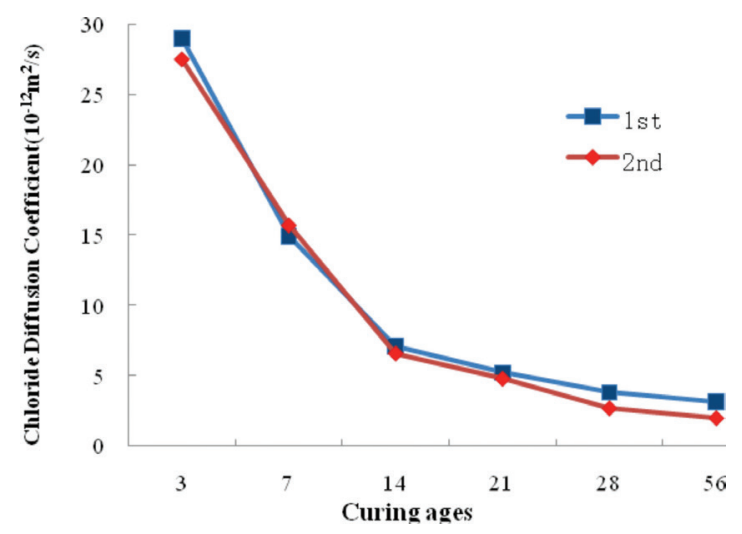

Figure 1. Influence of curing ages on concrete chloride diffusion coefficient.
It can be seen from Figure 1 that the chloride diffusion coefficient in concrete specimens decreases with increasing the curing days. The chloride diffusion coefficient reduces rapidly when curing days increase from 3 to 14 days; for the second test, the diffusion coefficient decreased from $27.5 \times 10^{-12}$ to $6.6 \times$ $10^{-12} \mathrm{~m}^{2} / \mathrm{s}$; further extending the concrete curing days does not significantly reduce the chloride diffusion coefficient. It can also be seen that the chloride diffusion coefficients of the two results are very close, which shows that the quality of the raw material is relatively stable and the reproducibility of the test method is relatively good.

\subsection{Concrete chloride diffusion coefficient under outdoor curing condition}

The influence of curing ages on chloride diffusion coefficient of concrete under outdoor curing condition is given in Figure 2.

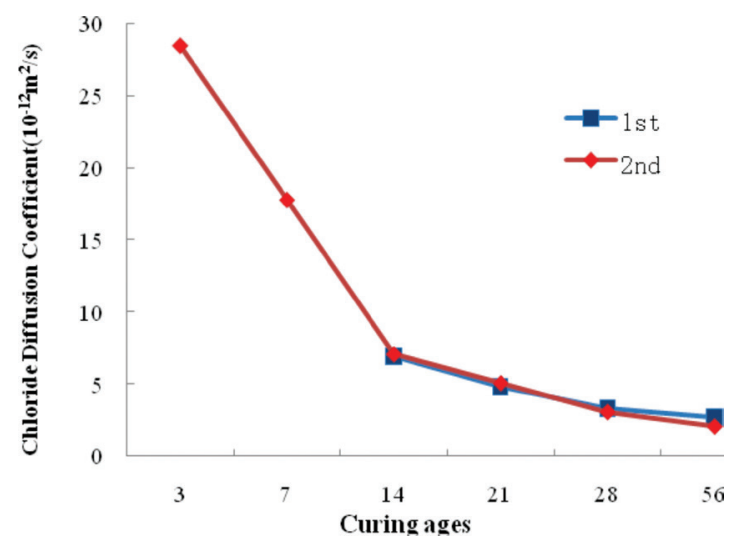

Figure 2. Influence of outdoor curing days on concrete chloride diffusion coefficient.

It can be seen from Figure 2 that the concrete chloride diffusion coefficient decreases with increasing the curing ages. For the first test period, the chloride diffusion coefficient of specimens for 28 days is $3.3 \times 10^{-12} \mathrm{~m}^{2} / \mathrm{s}$, and for the second test, the chloride diffusion coefficient of specimens for 28 days is $3.1 \times 10^{-12} \mathrm{~m}^{2} / \mathrm{s}$. Both of them meet the requirements of durability design for the immersed tube tunnel.

\subsection{Influence of curing temperature on anti-chloride-permeability of concrete}

The chloride diffusion coefficient under different curing conditions of concrete specimens are compared, and the results are shown in Table 2.

It can be seen from Table 2 that the chloride diffusion coefficient of concrete specimens under outdoor curing condition is slightly below that under the standard curing condition in the first experiment under the same curing days, while in the second experiment, 
Table 2. The chloride diffusion coefficients of specimens under different curing conditions.

\begin{tabular}{lcccccc}
\hline Curing conditions & \multicolumn{6}{c}{ Chloride diffusion coefficient $\left(\times 1 \mathbf{1 0}^{-\mathbf{1 2}} \mathbf{~}^{2} \mathbf{s}\right)$} \\
\cline { 2 - 7 } & $\mathbf{3}$ & $\mathbf{7}$ & $\mathbf{1 4}$ & $\mathbf{2 1}$ & $\mathbf{2 8}$ & $\mathbf{5 6}$ \\
\hline Standard curing (1st) & 29.0 & 14.9 & 7.1 & 5.2 & 3.8 & 3.1 \\
Outdoor curing (1st) & - & - & 6.9 & 4.8 & 3.3 & 2.7 \\
Standard curing (2nd) & 27.5 & 15.7 & 6.6 & 4.8 & 2.7 & 2.0 \\
Outdoor curing (2nd) & 28.5 & 17.8 & 7.1 & 5.1 & 3.1 & 2.1 \\
\hline
\end{tabular}

the chloride diffusion coefficient of specimens is slightly higher than that under the standard curing condition. The reason may be that in the first experimental periods, the daily average temperature at the precasting site of the immersed tube is $25^{\circ} \mathrm{C}$, which is higher than the standard curing temperature, while in the second experimental periods, the daily average temperature at the pre-casting site of the immersed tube is $18^{\circ} \mathrm{C}$, which is lower than the standard curing temperature.

Typically, the hydration degree of cementitious materials can be characterized by testing the chemically combined water of hardened pastes. Influence of curing temperature on chemically combined water at different curing days is showed in Figure 3.

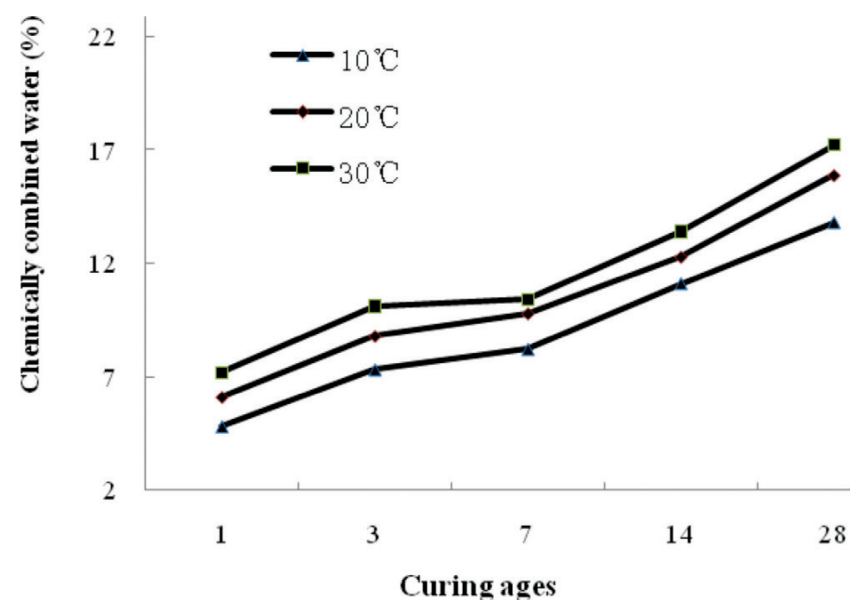

Figure 3. Influence of outdoor curing days on chemically combined water of pastes.

It can be seen from Figure 3 that the chemically combined water content increased with increasing the curing temperature; this indicates that improving the curing temperature can promote hydration degree of cementitious materials, so that the concrete at the same curing time has better resistance to chloride permeability.

\subsection{The correlation of chloride diffusion coefficient and concrete maturity value}

The relationship between concrete maturity value and chloride diffusion coefficient of standard curing concrete specimens is shown in Figure 4.

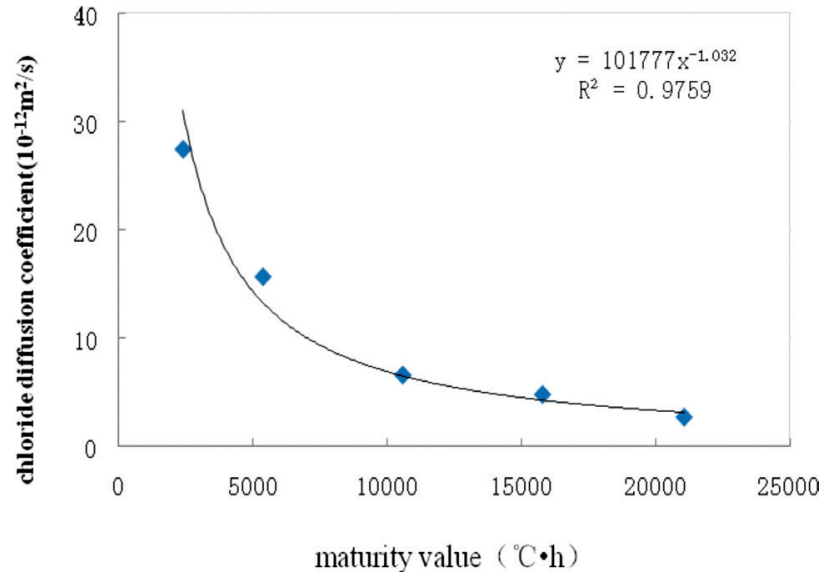

Figure 4. The correlation of chloride diffusion coefficient and concrete maturity value.

It can be seen from Figure 4 that the chloride diffusion coefficient decreased with increasing the maturity of concrete. In the maturity test period of concrete, there was a significant correlation between the chloride diffusion coefficient of indoor curing specimens and the concrete maturity value when expressed as a power function Equation (2) $\left(R_{2}=0.976\right)$.

$$
y=101777 X^{-1.032}
$$

Using the chloride diffusion coefficient of outdoor specimens with different curing ages, it can calculate the concrete theoretical maturity value by Equation (2). The theoretical maturity value and the measured value were listed in Table 3.

Table 3. The measured values and the theoretical value of maturity for outdoor specimens.

\begin{tabular}{lrrrrr}
\hline Type & \multicolumn{5}{c}{ Concrete maturity value $\left(\mathrm{h}^{-1}\right)$} \\
\cline { 2 - 6 } & $\mathbf{3}$ days & $\mathbf{7}$ days & 14 days & 21 days & 28 days \\
\hline Measured value & 2398 & 5374 & 10581 & 15788 & 21064 \\
Theoretical value & 2771 & 4673 & 10653 & 14680 & 23782 \\
Diversity (\%) & 16 & 15 & 1 & 7 & 13 \\
\hline
\end{tabular}

Table 3 shows that the measured values of the concrete maturity are close to the theoretical values at different curing ages. The difference between theoretical and measured values is less than $15 \%$ when the concrete curing days exceeded 7 days, which indicates the excellent accuracy of Equation (2).

It can be known from the above results that for this specific concrete mixture ratio, the maturity value can be used to calculate whether the concrete chloride diffusion coefficient meets the design requirements of concrete durability.

The chloride diffusion coefficient of concrete specimens for 28 days is $3.3 \times 10^{-12} \mathrm{~m}^{2} / \mathrm{s}$, less than the durability design requirements indicator, which was 
$6.5 \times 10^{-12} \mathrm{~m}^{2} / \mathrm{s}$. Therefore, the recommended indicator of chloride diffusion coefficient is $3.3 \times 10^{-12} \mathrm{~m}^{2} / \mathrm{s}$, the control indicator is $6.5 \times 10^{-12} \mathrm{~m}^{2} / \mathrm{s}$, and the corresponding recommended concrete maturity value is $21064^{\circ} \mathrm{C} \mathrm{h}^{-1}$ and the theoretical control value is $11606^{\circ} \mathrm{C} \mathrm{h}^{-1}$, respectively. Due to the differences between the measured value and the theoretical value of the concrete maturity value, the control of concrete maturity value of a $20 \%$ margin is $13926^{\circ} \mathrm{C} \mathrm{h}^{-1}$, while $13926 \mathrm{C} \mathrm{h}^{-1}$ has a control boundary value of immersed tube tunnel concrete maturity.

\section{CONCLUSIONS}

Based on the results and discussion, the following conclusions can be drawn.

1. The monitoring method of $w / b$ for fresh. The chloride diffusion coefficient of concretes decreases not only with increasing of curing ages but also with increasing curing temperature. The increase of both ages and temperature of curing can promote the hydration degree of cementitous materials and make them more resistive to chloride.

2. There was a significant correlation between the chloride diffusion coefficient of indoor curing specimens and the concrete maturity value when expressed as a power function $\left(R_{2}=0.976\right)$, and the calculated values of concrete maturity for outdoor specimens, which were obtained by using the power function, agrees well with the measured values.

3. When the concrete is placed in seawater, the recommended and the control value of concrete maturity are 21064 and $13926^{\circ} \mathrm{C} \mathrm{h}^{-1}$, respectively. The ages of the concrete placed in seawater can be appropriately adjusted by calculation when considering the external curing temperature and heat of hydration of cementitous.

\section{REFERENCES}

Leng, F. (2000). An experimental study on the properties of resistance to diffusion of chloride ions of fly ash and blast furnace slag concrete. Cement and Concrete Research, 30, 989-992.

Li, P. (2011). Influence of binder composition and concrete pore structure on chloride diffusion coefficient in concrete. Journal of Wuhan University of Technology (Materials Science), 26, 160-164.

Shi, M. (2002). Research on hydration properties of cement and fly ash composite gelled material. Journal of Building Materials, 5, 114-119.

Thomas, M. D. A. (2004). Performance of pfa in a marine environment-10-year results. Cement and Concrete Composites, 26, 5-20.

Wang, C. (2010). The application of the Concrete Maturity in wharf Cracks on the surface of a deck. Water Transport Engineering, 28, 141-144.

Wang, S. (2002). Investigation and analysis of South China seaport wharf concrete structure durability corrosion situation. Water Transport Engineering, 20, 8-12.

Zhang, Y. (2006). The hydration reaction of cement-fly ash pastes process. Journal of Southeast University, 36, 118-123. 